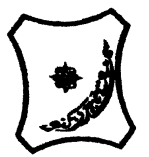

Bayero Journal of Pure and Applied Sciences, 11(2): 94 - 98

Received: February, 2018

Accepted: December, 2018

ISSN $2006-6996$

\title{
PHYTOCHEMICAL AND ANTIEMETIC STUDIES ON AQUEOUS ETHANOL EXTRACT OF THE ROOT OF Senna occidentalis (L.) LINK
}

\author{
Shehu, S., ${ }^{1 *}$ Saleh, I., ${ }^{1}$ Otokpa, S. U., ${ }^{1}$ Madaki, E. V. ${ }^{1}$ and Sambo, Z. A. ${ }^{1}$ \\ ${ }^{1}$ Department of Pharmacognosy and Drug Development, Ahmadu Bello University, Zaria. Nigeria \\ Author for Correspondence: (shehus3621@yahoo.com, 234-08134924454)
}

\begin{abstract}
Senna occidentalis (Caesalpiniaceae) is a pan tropical shrub plant widely distributed in warm regions of the world. The root infusion of the plant has been used for the treatment of gastro-intestinal disorders including emesis. The current research is aimed at evaluating the antiemetic property of the aqueous ethanol extract and solvent fractions of the root and also verifying the classes of phytochemicals in the extract and fractions. The $L D_{50}$ of the extract and its solvent fractions was determined. The antiemetic property was evaluated using copper sulphate induced emesis in chicks while phytochemical screening was carried out using standard methods. The three doses of the extract (300, 150 and $75 \mathrm{mg} / \mathrm{kg}$ ) conferred dose-independent protection and inhibition against retching compared to the control group. At a dose of $150 \mathrm{mg} / \mathrm{kg}$, the extract completely (100\%) prevented copper sulphate-induced emesis comparable to promethazine at $150 \mathrm{mg} / \mathrm{kg}$, the standard antiemetic used. Other doses of the extract 300 and $75 \mathrm{mg} / \mathrm{kg}$ showed lower effect relatively. Two of the three fractions of the ethanol extract; Hexane and n-butanol fractions at $150 \mathrm{mg} / \mathrm{kg}$ dose protected against retching in a similar degree (100\%) demonstrated by the crude ethanol extract and the standard antiemetic promethazine at $150 \mathrm{mg} / \mathrm{kg}$, while ethyl acetate fraction exhibited its maximum protection (100\%) at the lowest dose used (75mg/kg).The extract and all of its solvent fractions were found to be non-lethal at up a dose of $5000 \mathrm{mg} / \mathrm{kg}$ via the oral route. Identified phytochemicals in the ethanol extract include; unsaturated steroids, cardiac glycosides, saponins and tannins. These phytochemicals were found to be distributed across different fractions of the extract in order of their polarity; Steroids and resins in the n-hexane fraction, Cardiac glycosides, unsaturated sterols, saponins and tannins in the Ethylacetate and $\mathbf{N}$-butanol fractions. In addition to the ones mentioned, ethyl acetate fraction contains flavonoids. The observed antiemetic activity of the extract and fractions could be due to one or some of these phytochemicals present.
\end{abstract}

Key words: Antiemetic, Copper sulphate, Phytochemicals, Senna occidentalis

\section{INTRODUCTION}

Plants constitute the cornerstone of traditional medicine. It is a common practice in Nigeria and other parts of the world to use plant in the form of crude extracts, decoction, infusion or tincture to treat common infections and disorders (Evans, 2009). One of the most common among these disorders is emesis.

According to Bhandari et al.,(1991), emesis encompasses the forceful expulsion of the contents of stomach via the mouth or sometimes the nose. It is a response of biological systems for drug side effects, disease co-morbidities and defense against food poisoning (Fukui, 1994) and other conditions such as; morning sickness, motion sickness, myocardial infarction (Katzung, 2001).
The currently used antiemetics are associated with a number of side effects, low efficacy especially in patients undergoing cancer chemotherapy. Some these agents are expensive beyond the reach of so many individuals affected by this disorder.

In search for new antiemetic agents (expected to be cheaper and safer than the existing ones). A lot of attention has been paid to natural sources. Some of the different bioactive compounds found to exhibit significant antiemetic property include: cannabinoids, chalcones, flavonoids, hydroxycinnamic acids, lignans, phenylpropanoids, polysaccharides, saponins and terpenes (Akita et al., 1998). 
Senna occidentalis is a small shrub, about $3 \mathrm{ft}$ high, belonging to the family, Caesalpiniaceae. The root infusion of the plant has been used for the treatment of stomach upset in babies in Madagascar (Burkill, 1995). The current research is aimed at validating this folkloric use (treatment of emesis) and screening for the phytochemical compounds present in the extract and its solvent fractions.

\section{MATERIALS AND METHODS Collection, Identification and Preparation of the Plant Material}

The aerial part of the plant was collected from around Ahmadu Bello University Dam, Zaria on the $3^{\text {rd }}$ of May 2016. The collected plant was taken to the herbarium section of Biological Sciences Department, Ahmadu Bello University Zaria for identification. The plant was identified by comparison with the existing specimen by Mr. Namadi Sunusi and a voucher number 3106 issued for reference. The fresh root of the plant was then collected sliced, shade dried, ground to coarse powder and kept for future use.

\section{Extraction and Fractionation}

The dried coarse powder $(930 \mathrm{~g})$ was cold macerated in 3 liters of $70 \%$ ethanol in a covered wide mouth jar for 3days, filtered through cotton plug and Whatmann's filter paper and finally concentrated using rotary evaporator. The dried extract was then weighed and kept in a dessiccator $(61.12 \mathrm{~g})$. The partitioning of the extract was carried out according to the method described by Woo et al., (1980). A portion $(56.47 \mathrm{~g})$ of the aqueous ethanol extract was suspended in water and partitioned across nHexane, Ehylacetate and N-butanol, successively, yielding; hexane fraction (HF), ethylacetate fraction (EA) and n-butanol faraction (NB) fractions

\section{Experimental Animals}

Four days old cockerels $(25-50 \mathrm{~g})$, were obtained from National Animal Production Research Institute Shika, Zaria. The animals were maintained in a well ventilated room, fed on Excel feeds (Feeds Masters, Ilorin) and water supplied ad libitum.

\section{Phytochemcial Screening}

Phytochemical screening was carried out on the aqueous ethanol extract, its n-hexane, ethylacetate and n-butanol fractions using standard method of analysis (Evans, 2009).

\section{Acute Toxicity Study}

The median lethal dose $\left(L_{50}\right)$ was determined using the method of Lorke (1983). The method consists of two phases. In the first phase, three groups of three chicks each, were administered with crude ethanol extract of the root of Senna occidentalis at doses of 10,100 and $1000 \mathrm{mg} / \mathrm{kg}$ via the oral route and observed for signs of toxicity and mortality within $24 \mathrm{~h}$. In the second phase, four groups of one chick each were treated with four more specific doses of the extract; 1200, 1600, 2700, and $5000 \mathrm{mg} / \mathrm{kg}$ based on the result obtained from the first phase. The same procedure was repeated for each of the solvent fractions of the extract (nhexane, ethylacetate and n-butanol) using similar doses. The $\mathrm{LD}_{50}$ value was determined by calculating the geometric means of the lowest dose that caused death and the highest dose for which the animals survived.

\section{Antiemetic Study}

The antiemetic effect was determined following protocols of Tehseen et al. (2012). All the chicks initially fasted for 24hrs were divided into six groups of six animals each, weighed and labeled. Group I received $0.9 \%$ normal saline $(10 \mathrm{ml} / \mathrm{kg})$ orally, as the negative control. Group II, III and IV received oral dose of crude ethanol extract of the root of Senna occidentalis dissolved in $0.9 \%$ normal saline at doses of $300 \mathrm{mg} / \mathrm{kg}, 150 \mathrm{mg} / \mathrm{kg}$ and $75 \mathrm{mg} / \mathrm{kg}$ respectively, while Group V received promethazine the standard anti-emetic drug at a dose of $150 \mathrm{mg} / \mathrm{kg}$ orally. Each of the chicks was allowed to stabilize for 10 minutes in large container after which they were then administered with copper sulphate orally at a dose of $50 \mathrm{mg} / \mathrm{kg}$. The observed number of retching in each of the group was recorded for 10 minutes duration. The ability of the test extract to prevent retching( indicated by percentage protection), decrease the frequency of retching and or decrease the mean number of retching was considered an indication of its antiemetic activity. The percentage inhibition of retching was evaluated by using the formula below:

The same procedure was carried out using nhexane, ethylacetate and n-butanol fractions of the aqueous ethanol extract of $S$. occidentalis and using similar doses as determined from their respective $L_{50}$ values.

Inhibition $(\%)=\frac{A-B}{A} X 100 \quad$ (Tehseen et al. 2012)

Where: $A=$ Frequency of retching in the control group and $\mathrm{B}=$ Frequency of retching in the test group 


\section{Statistical Analysis}

All data were expressed as mean \pm SEM and percentages (\%) where appropriate. One way analysis of variance (ANOVA) followed by Dunnett's post hoc test for multiple comparison were used to determine the level of significance obtained. Results were regarded significant at $\mathrm{P}<0.05$.

\section{RESULTS}

\section{Phytochemical Screening}

The different classes of phytochemicals in the ethanol extract include; unsaturated steroids, cardiac glycosides, saponins and tannins. These phytochemicals were found to be distributed across different solvents used to fractionate the extract in order of their polarity; Steroids and resins in the n-hexane fraction, Cardiac glycosides, unsaturated sterols, saponins and tannins in the Ethylacetate and $\mathrm{N}$-butanol fractions. In addition to the ones mentioned, ethyl acetate fraction contains flavonoids.

\section{Acute Toxicity Study}

The extract and all of its solvent fractions ( $n$ hexane, ethylacetate and n-butanol) has not inflicted any sign of toxicity or death to the chicks even at the highest dose $(5000 \mathrm{mg} / \mathrm{kg}$ ) used. Hence, 300, 150 and $75 \mathrm{mg} / \mathrm{kg}$ doses were used for the antiemetic study.

\section{Antiemetic Study}

The three doses $(300,150$ and $75 \mathrm{mg} / \mathrm{kg}$ ) of ethanol extract of the roots of Senna occidentalis used conferred dose-independent protection and inhibition against retching compared to the control group. At a dose of $150 \mathrm{mg} / \mathrm{kg}$, the extract completely $(100 \%)$ block copper sulphate-induced emesis observed in the control group, comparable to promethazine at $150 \mathrm{mg} / \mathrm{kg}$. Other doses of the extract 300 and $75 \mathrm{mg} / \mathrm{kg}$ showed lower effect relatively; conferring 50 and $83.33 \%$ protection respectively. Also at these doses, the extract exhibited lower effect in decreasing the number of retches observed in the control, 41.53 and $39.52 \%$ respectively.

Two of the three fractions of the ethanol extract; Hexane and n-butanol fractions at $150 \mathrm{mg} / \mathrm{kg}$ dose, protected against retching in a similar degree $(100 \%)$ demonstrated by the crude ethanol extract and the standard antiemetic promethazine at $150 \mathrm{mg} / \mathrm{kg}$, while ethyl acetate fraction exhibited its maximum protection $(100 \%)$ at the lowest dose used $(75 \mathrm{mg} / \mathrm{kg})$. Other different doses of these fractions of the extract exhibited varying degrees of protection and inhibition against retching as shown in the table. Similarly, there is no statistically significant difference of MNR in the different groups (fractions of the extract) and the control. These results are as shown in the table below:

Table 1. Antiemetic Activity of Aqueous Ehanol Extract and Solvent Fractions of the Root of Senna occidentalis

\begin{tabular}{lccc}
\hline Treatment & MNR \pm SEM & $\% I R$ & $\%$ PP \\
\hline Control & $24.80 \pm 13.01$ & 0.00 & .00 \\
ES 300mg/kg & $14.50 \pm 13.50^{\text {NS }}$ & 41.53 & 50.00 \\
ES 150mg/kg & - & 100.00 & 100.00 \\
ES 75mg/kg & $15.00 \pm 0.00^{\text {NS }}$ & 39.52 & 83.33 \\
HF 300 & $62.00 \pm 0.00^{\text {NS }}$ & 58.35 & 83.33 \\
HF 150 & - & 100.00 & 100.00 \\
HF 75 & $67.50 \pm 7.50^{\text {NS }}$ & 54.64 & 67.67 \\
EA 300 & $42.00 \pm 20.66^{\text {NS }}$ & 0.00 & 50.00 \\
EA 150 & $32.00 \pm 18.50^{\text {NS }}$ & 20.16 & 33.33 \\
EA 75 & - & 100.00 & 100.00 \\
NB 300 & $30.33 \pm 23.97^{\text {NS }}$ & 40.00 & 50.00 \\
NB 150 & - & 100.00 & 100.00 \\
NB 75 & $11.00 \pm 5.02^{\text {NS }}$ & 20.00 & 33.33 \\
PMZ 150mg/kg & - & 100.00 & 100.00 \\
\hline
\end{tabular}

NS=not statistically significant at $P<0.05, M N R=$ Mean number of retching,

$\% I R=$ Percentage inhibition of retching, $\% P P=$ Percentage protection against retching

$\mathrm{ES}=$ ethanol extract, $\mathrm{HF}=$ hexane fraction, $\mathrm{EA}=$ ethylacetate fraction, $\mathrm{NB}=$ butanol fraction and $\mathrm{PMZ}=$ promethazine 


\section{DISCUSSION}

Although, the extract and its solvent fractions (Hexane and butanol fraction) at $150 \mathrm{mg} / \mathrm{kg}$, ethyl acetate fraction at $75 \mathrm{mg} / \mathrm{kg}$ demonstrated excellent protection (100\%) against copper sulphate-induced emesis, There was no significant difference among the different groups regarding the mean number of retching (MNR). This may likely be due to the wide difference with which the animals responded to the copper sulphate during the induction phase.

Recently, much attention has been directed towards extracts and biologically active compounds isolated from plant species. The current investigation report revealed that ethanol extract of the root of Senna occidentalis and its various solvent fractions possessed phytochemicals that directly or indirectly contribute to the antiemetic activity of the plant. The search for new antiemetic agents from natural sources continues to emphasize mechanism based approaches, involving discrete based cellular and biochemical targets (Salman et al., 2014). Some of the bioactive compounds that were exploited for these targets and many of which were found to be present in the extract and fractions of the plant, include; cannabinoids, chalcones, diarylheptanoids, flavonoids, glucosides, hydroxycinnamic acids, lignans, phenylpropanoids, polysaccharides, saponins, steroids and terpenes (Salman et al., 2014). Steroids were thought to reduce emesis especially in post-operative nausea and vomiting

\section{REFERENCES}

Akita Y, Yang Y, Kawai T, Kinoshita K, Koyama K, Takahashi K, Wantanabe K. (1998). Newassay method for surveying antiemetic compounds from natural sources. Natural Product Sciences 4, 72-77.

Bhandari P, Andrews PLR. (1991). Preliminary evidence for the involvement of the putative 5-HT4 receptor in zacoprideand copper sulfate-induced vomiting in the ferret. European Journal of Pharmacology 204, 273-280.

Burkill, H.M.(1995). The Useful Plants of West Africa.Vol.3. Royal Botanical Garden, Kew.England.Pp 162.

Evans, W. C. (2009): Trease and Evans pharmocognosy. Elseviers. Pp. 10 $-11$.

Fukui H, Yamamoto M, Sasaki S, Sato S. (1994). Possible involvement of peripheral 5HT4 receptors in copper sulfateinduced vomiting in dogs. European Journal of Pharmacology 257, 47- 52. by decreasing production of inflammatory mediators which are known to act on the vomiting center of the brain (Tzeng et al., 2000). Resins possess the ability to form chelate complexes with metals such as copper, magnesium and iron (Hosseinzadeh et al., 2008). This ability to form chelates with copper may be responsible for the observed antiemetic activity of resins as it reduces peripheral stimulation of emesis by copper sulphate by reduction of the copper content (Hosseinzadeh et al., 2008). Although the present research may have justified the folkoric use of this plant for the treatment of emesis, the actual mechanism for which the plant extract and fraction act is not known but can be inferred that it may be acting by blocking of peripheral $5 \mathrm{HT}_{4}$ receptors in the GI. This is because, $\mathrm{CuSO}_{4}$ induces emesis by peripheral action (Hossein et al., 2005) and peripheral $5 \mathrm{HT}_{4}$ plays an important role in this action (Bhandari et al., 1991; Fukui et al., 1994). Hence, Senna occidentalis root extract and fractions may said to exhibit peripheral antiemetic action.

\section{CONCLUSION}

The result of the studies indicated that; the aqueous ethanol extract and solvent fractions of the root of Senna occidentalis demonstrated dose-independent protection against copper sulphate-induced emesis and this may justify its folkloric use in the treatment of emesis.

Hossein H, Mashallah M, Akbar G. (2005). Antiemetic effect of Menthaxpiperita aerial parts extracts in young chickens. Iranian Journal of Pharmaceutical Sciences 1, 21-24.

Hosseinzadeh $\mathrm{H}$, Mirshojaeian M, Razavi BM. (2008). Antiemetic effect of Pistacia Vera L. (Pistachio)leaves and nuts aqueous extracts in young chicken.Pharmacologyonline; 2: 568571.

Katzung B.G. (2001). Basic and Clinical Pharmacology. First edition. SalembaMedika. Jakarta. Pp.89-92.

Lorke, D. (1983): A new Approach to Practical Acute Toxicity Testing. Archives of Toxicology 54:275-287.

Salman Ahmed, Muhammad MohtasheemulHasan and Syed Waseemuddin Ahmed (2014). Natural antiemetics: An overview. 13-14. 
Tehseen Quds, S. A. (2012). Antiemetic activity of Acalipha fimbriata Schumach. \& Thonn., Acalypha ornata Hochst., and Acalypha wilkesiana cv. godseffiana Muell Arg. Phytophamacology, 335340.

Tzeng JI, TsweiTS, Tang CS, (2000). Dexamethasone alone does not prevent post-operative nausea vomiting in women undergoing dilatation and curettage: a comparison with droperidoland saline. ActaAnaesthesiolScand; 38:137-142.
Woo M.G, Shin H.Y and Kang K.S (1980): Chemistry and Pharmacology of Flavone C- $\quad$ glycosides from Ziziphus seeds. The Korean Journal of Pharmacognosy, 11(34) 141-148.

World Health Organization (2002). Traditional Medicine Strategy 2002-2005. Geneva: WHO.

World Health Organization (2003). Traditional Medicine, Fact Sheet No. 134, Available at http://www.who.int/mediacentre/factshe ets/fs134/en/ 